\title{
Multi-Vector Fluorescence Analysis of the xpt Guanine Riboswitch Aptamer Domain and the Conformational Role of Guanine ${ }^{\dagger}$
}

\author{
Michael D. Brenner, ${ }^{\ddagger}$ Mary S. Scanlan, ${ }^{\ddagger}$ Michelle K. Nahas, ${ }^{\S}$ \\ Taekjip Ha, ${ }^{\ddagger}$, ,q,* and Scott K. Silverman ${ }^{\ddagger *}$ \\ ${ }^{\ddagger}$ Department of Chemistry, ${ }^{\S}$ Department of Physics and Center for the Physics of Living Cells, \\ University of Illinois at Urbana-Champaign, Urbana, Illinois 61801 \\ and ${ }^{\top}$ Howard Hughes Medical Institute, Urbana, Illinois 61801
}


Figure S1. In-line probing assays for the three aptamer domain variants. (A) P1-P2 variant. (B) P1-P3 variant. (C) P2-P3 variant. See Experimental Procedures for assay (37) and quantitation methods. The numbered single-stranded regions show the expected decreases in cleavage in the presence versus absence of $1 \mu \mathrm{M}$ guanine ( $\mathrm{G}$ versus -; gold vs. black line graphs to the right of each gel image). In contrast, $1 \mu \mathrm{M}$ adenine has no effect. Control regions marked " $\mathrm{C}$ " show little dependence upon guanine. In the line graphs, the peak marked " $n$ " was used for normalization of the - and G data. Collectively, the in-line probing data confirm that $\mathrm{Cy} 3 / \mathrm{Cy} 5$ dye labeling of the variants does not significantly impact their ability to bind guanine. Precise $K_{\mathrm{d}}$ values for guanine for the labeled variants were not determined; we cannot rule out modest changes in $K_{\mathrm{d}}$ due to the presence of the dyes. In particular, P2-P3 shows less guanine-dependent protection than do the other two variants. Nevertheless, P2-P3 does show a substantial FRET change upon introduction of guanine (Figure 4), indicating that significant guanine binding still occurs. P1-P2 and P1-P3 were each probed using an RNA that has an unhybridized 5'overhang, corresponding directly to the RNA used in the ensemble FRET measurements. For P2-P3, the illustrated data were obtained with an RNA that altogether lacks the 5'-overhang; essentially equivalent data were obtained using the RNA that has an unhybridized $5^{\prime}$-overhang (data not shown). In the illustrated data, region 4 of P2-P3 - in particular, the lowest band that, by comparison with the P1-P2 and P1-P3 data, is expected to decrease most in intensity upon guanine binding - could not be fully resolved and quantified due to its proximity to the 5 '-terminus.

Figure S2. Purine specificity for the conformational changes observed in the P1-P2 variant. Data are similar to the histograms of Figure $2 \mathrm{C}$, except that $500 \mathrm{nM}$ or $50 \mu \mathrm{M}$ adenine was included as indicated (all in the absence of $\mathrm{Mg}^{2+}$ ).

Figure S3. Comparison of smFRET data for the P1-P2 and P2-P3 variants. (A) Rate comparison of P1-P2 and P2-P3 at $10 \mu \mathrm{M} \mathrm{Mg}^{2+}$. The high $(E>0.5)$ and low $(E<0.5)$ FRET dwell times for the P1-P2 variant were recorded without (left) and with (right) $500 \mathrm{nM}$ guanine at $10 \mu \mathrm{M} \mathrm{Mg}^{2+}$. The inverse dwell times for high and low FRET values $\left(k_{\text {unfold }}\right.$ and $\left.k_{\text {fold }}\right)$ were plotted for both P1-P2 and P2-P3. Without and with guanine, respectively, 171 and $101 \mathrm{P} 1-\mathrm{P} 2$ variant molecules were analyzed to obtain $k_{\text {unfold }}$ and $k_{\text {fold. }}$ (B) Heterogeneity in dynamics of P1-P2 and P2-P3. The average transition rates shown in panel A indicate a contribution from fast $\left(>1 \mathrm{~s}^{-1}\right)$ FRET fluctuations for the P1-P2 variant. On the left are depicted representative traces in the absence of $\mathrm{Mg}^{2+}$ and guanine exhibiting fast dynamics for P1-P2 and both fast and slow $\left(<1 \mathrm{~s}^{-1}\right)$ dynamics for P2-P3. On the right, the distributions of fast, slow, and mixed dynamics are presented for P1-P2 and P2-P3 with different concentrations of $\mathrm{Mg}^{2+}$ and guanine. In all conditions analyzed, over $50 \%$ of P1-P2 traces exhibited only slow dynamics, while a majority of the traces for the P2-P3 variant displayed both fast and slow dynamics. Both variants are capable of fast dynamics, but P2-P3 exhibits more heterogeneity within individual traces. Therefore, the average trace for the P1-P2 variant differs from the average trace for P2-P3 variant in terms of dynamic behavior, although the average FRET dwell times and the transition rates for both variants are comparable.

Figure S4. Stabilization by guanine of the high- $E$ state of the P2-P3 variant. At each $\mathrm{Mg}^{2+}$ and guanine concentration, the value of $\Delta \mathrm{G}^{\circ}$ was calculated as $-\mathrm{RT} \cdot \ln \left(k_{\text {fold }} / k_{\text {unfold }}\right)$. Guanine stabilizes the high-FRET state by $\Delta \Delta \mathrm{G}^{\circ}=0.51 \pm 0.26 \mathrm{kcal} / \mathrm{mol}$ at $100 \mu \mathrm{M} \mathrm{Mg}^{2+}$ and $0.44 \pm 0.40 \mathrm{kcal} / \mathrm{mol}$ at $1 \mathrm{mM} \mathrm{Mg}^{2+}$. Error bars represent propagation of the standard errors of $k$ values from Figure $4 \mathrm{E}$. 
Figure S5. Heterogeneity in the folded-state and unfolded-state dwell times of the G riboswitch aptamer domain. (A) The high- $E$ (folded state) and low- $E$ (unfolded state) dwell times were averaged to yield a single value for each of the indicated number of P2-P3 molecules under each buffer condition. The results are represented in $2 \mathrm{D}$ scatter plots that compare the average time each molecule spent in the folded or unfolded state during data acquisition ( $1 \mathrm{~min})$ (17). (B) Scatter plots were constructed for the P1-P2 variant with and without $500 \mathrm{nM}$ guanine at $10 \mu \mathrm{M} \mathrm{Mg}^{2+}$. The log averages of the folded-state and unfolded-state dwell time values for all molecules under each condition were calculated to determine the average high-FRET and low-FRET dwell times as well as the values for $k_{\text {fold }}$ and $k_{\text {unfold }}$ (Figures 4E and S3A). 
Figure S1. In-line probing assays for the three aptamer domain variants.

\section{A. P1-P2}
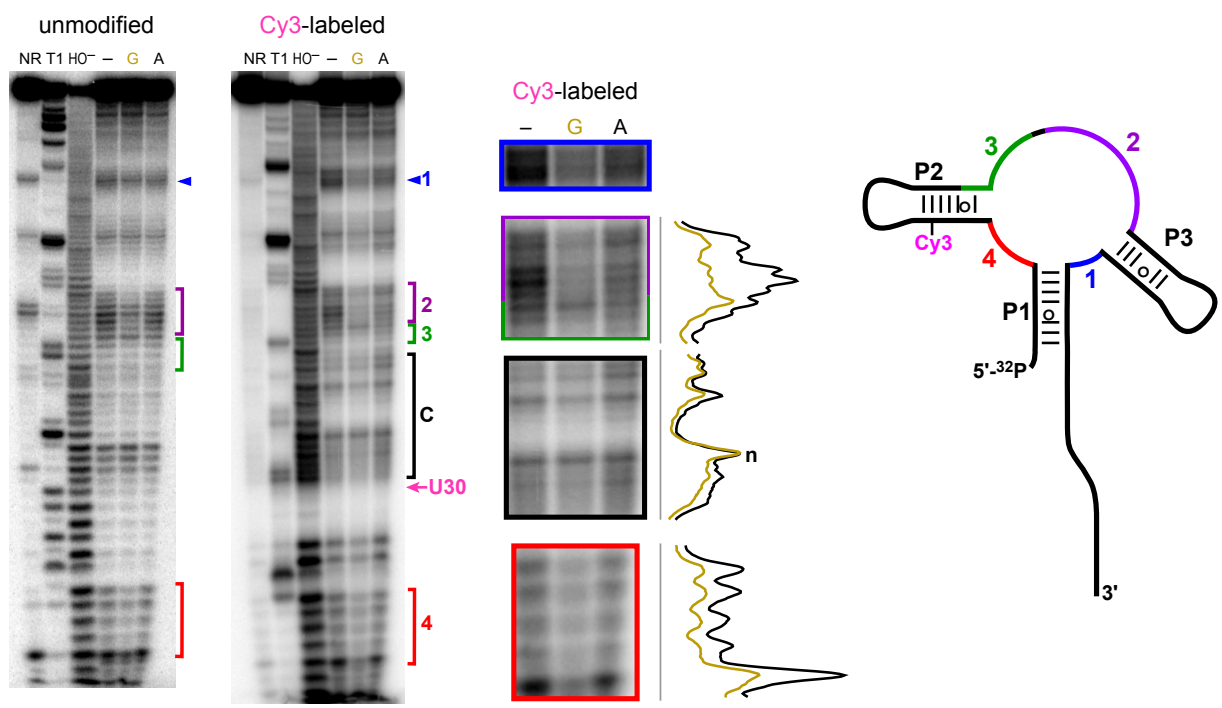

\section{B. P1-P3}

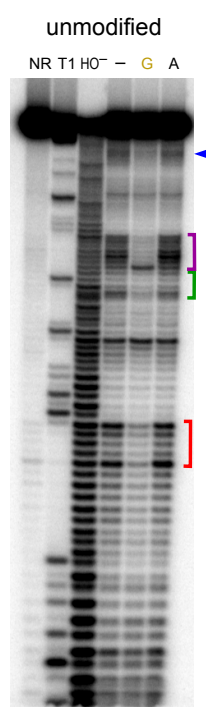

Cy3-labeled

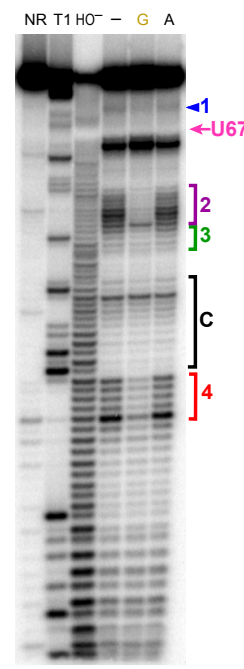

Cy3-labeled
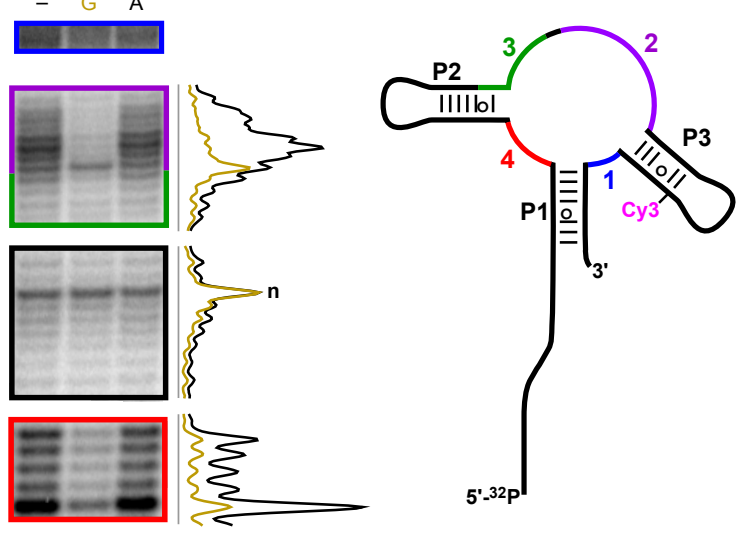

\section{P2-P3}
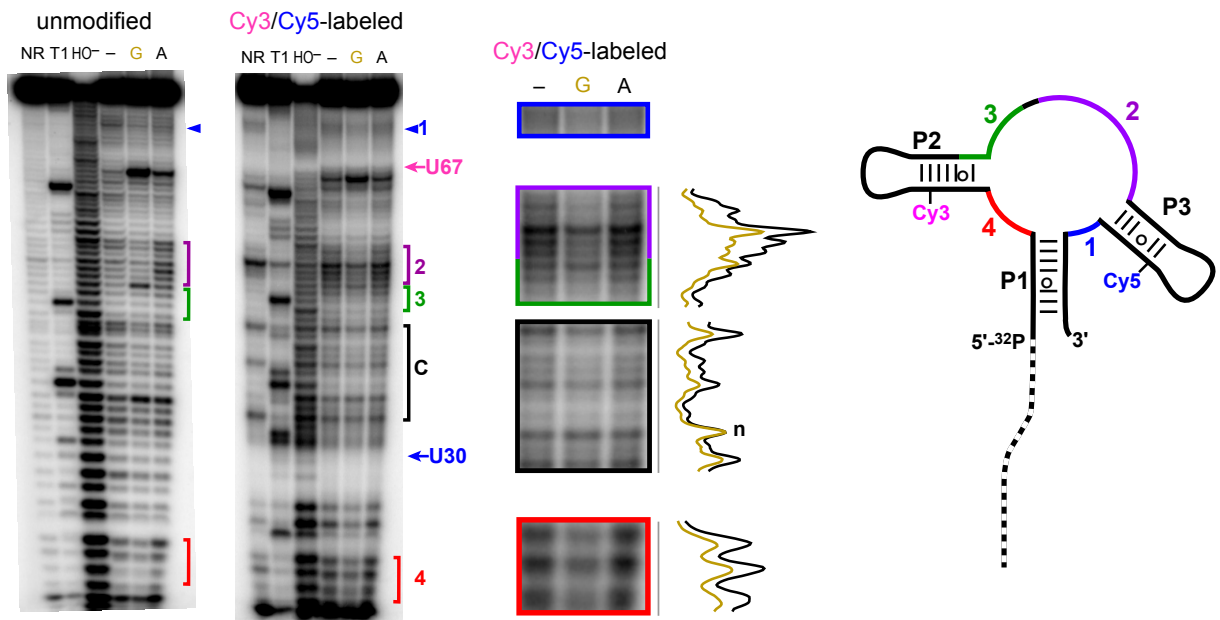
Figure S2. Purine specificity for the conformational changes observed in the P1-P2 variant.

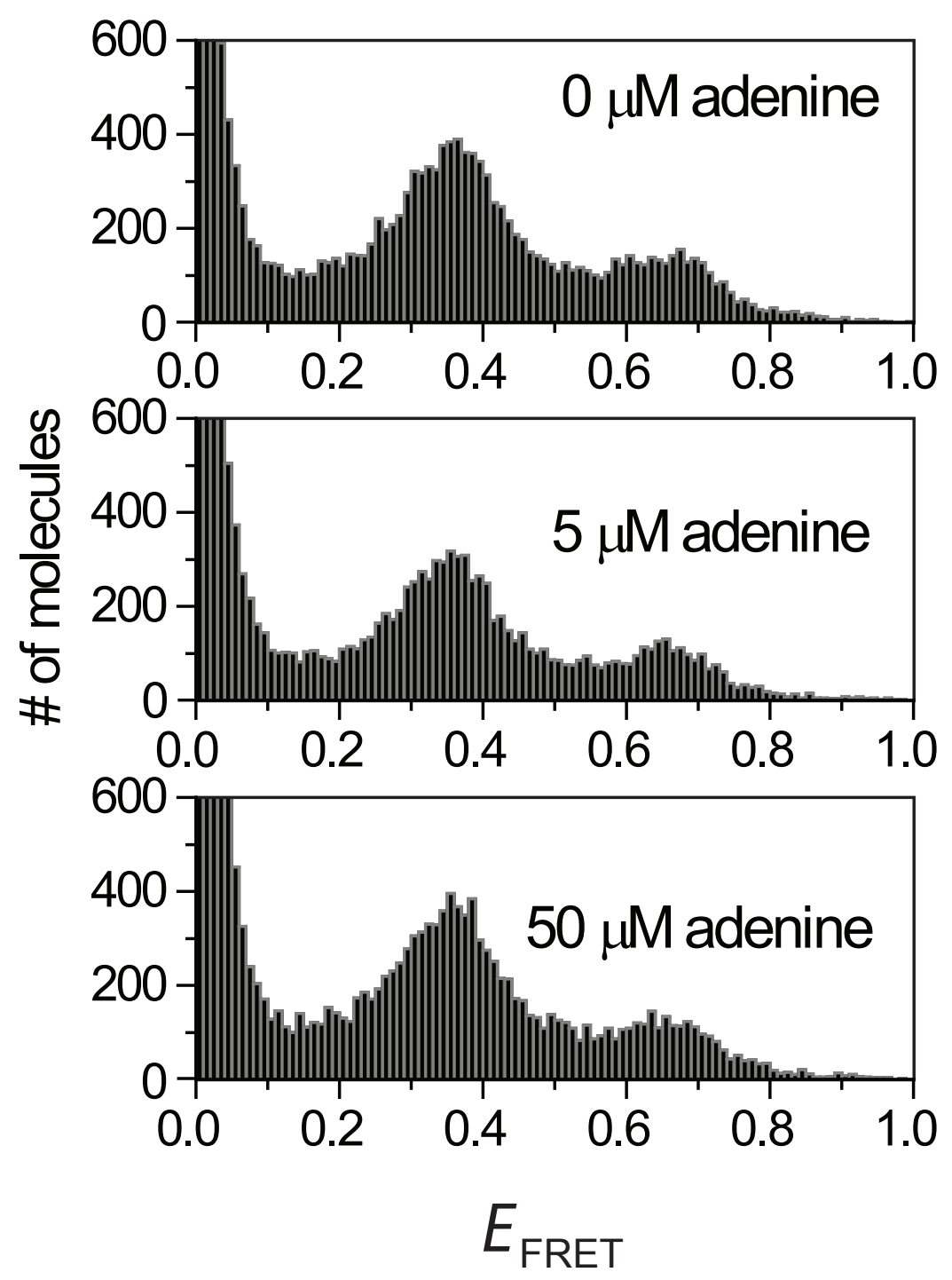


Figure S3. (A) Rate comparison of P1-P2 and P2-P3 at $10 \mu \mathrm{M} \mathrm{Mg}^{2+}$.
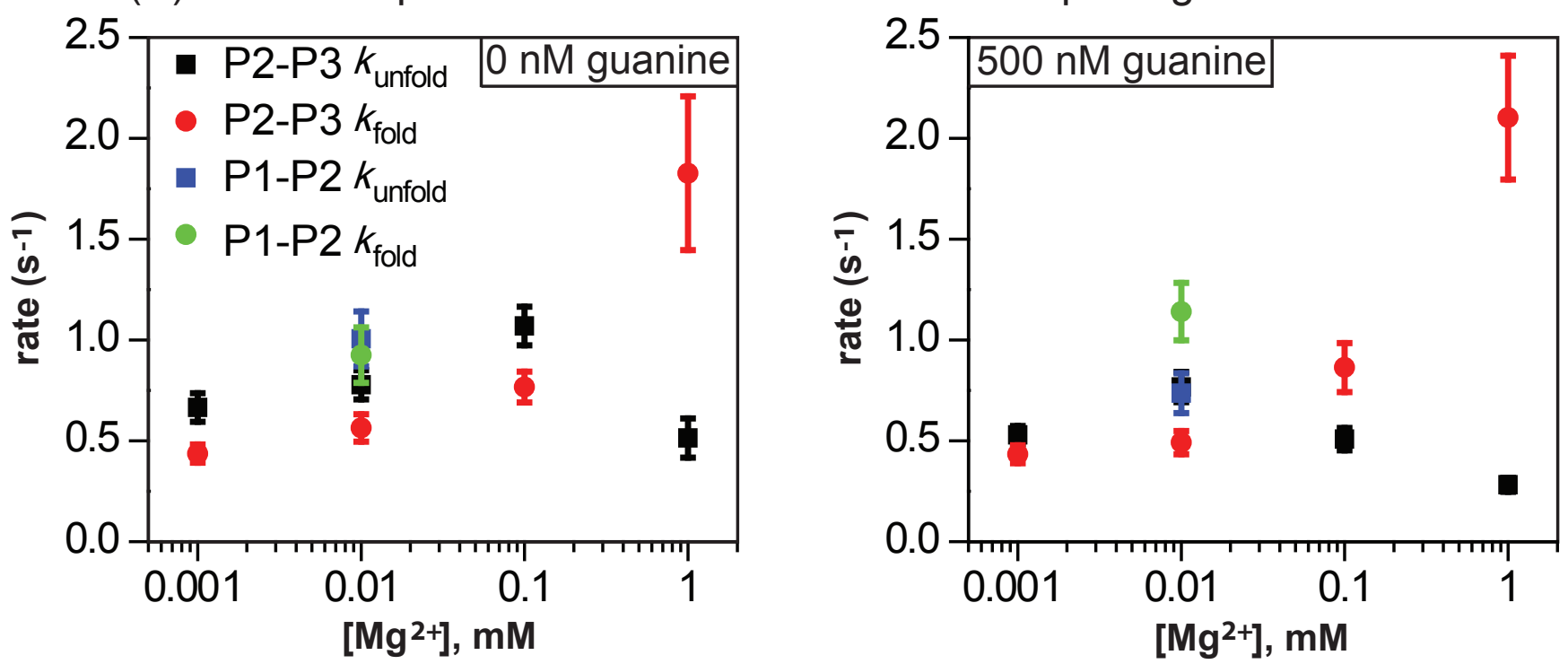

(B) Heterogeneity in dynamics of P1-P2 and P2-P3.

P1-P2

$0 \mathrm{mM} \mathrm{Mg}{ }^{2+}, 0 \mathrm{nM}$ guanine
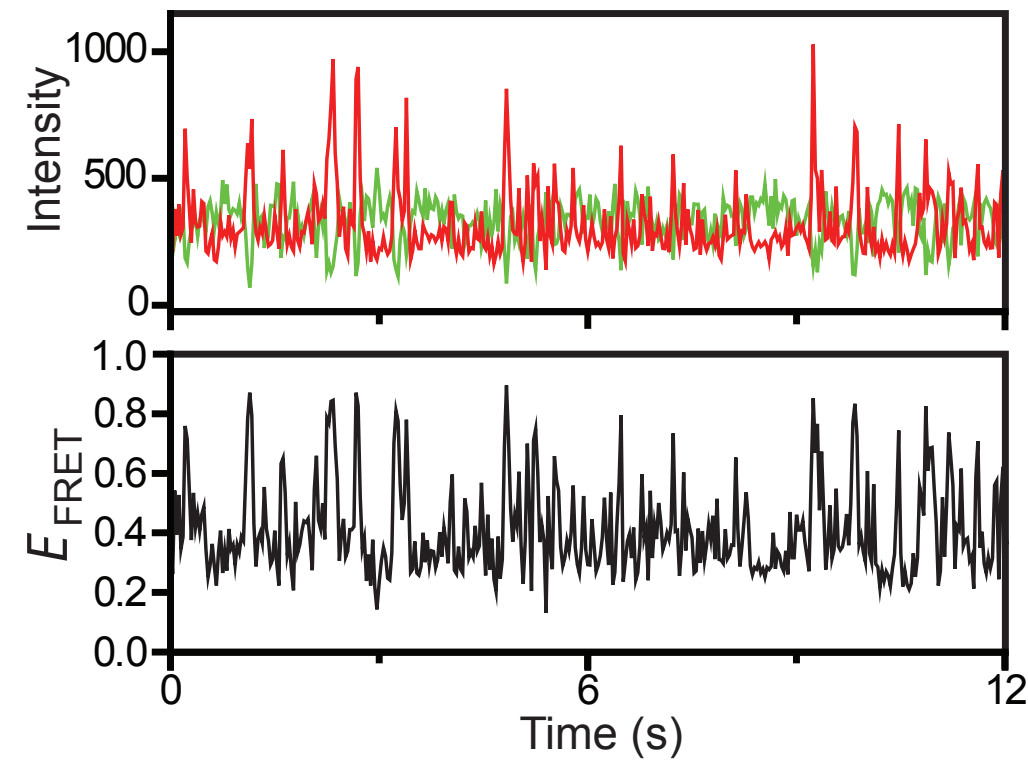

P2-P3

$0 \mathrm{mM} \mathrm{Mg}{ }^{2+}, 0$ nM guanine
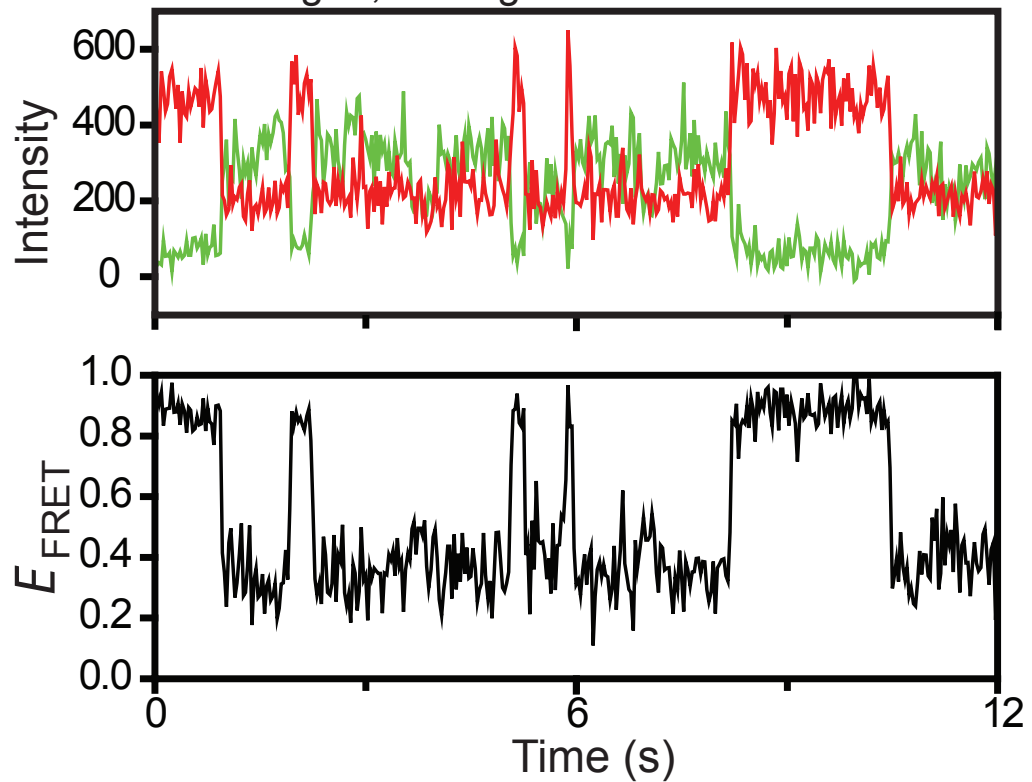

Survey of P1-P2 dynamic behavior

\begin{tabular}{|l|l|l|l|}
\hline Buffer & $\begin{array}{l}\% \\
\text { slow }\end{array}$ & $\begin{array}{l}\% \\
\text { fast }\end{array}$ & $\begin{array}{l}\% \\
\text { both }\end{array}$ \\
\hline $\begin{array}{l}0 \mu \mathrm{M} \mathrm{Mg} \\
0 \mathrm{nM} \mathrm{G}\end{array}$ & 53.4 & 29.5 & 17.0 \\
\hline $\begin{array}{l}10 \mu \mathrm{M} \mathrm{Mg} \\
0 \mathrm{nM} \mathrm{G}\end{array}$ & 62.1 & 17.4 & 20.5 \\
\hline $\begin{array}{l}0 \mu \mathrm{M} \mathrm{Mg}{ }^{2+} \\
500 \mathrm{nM} \mathrm{G}^{2+}\end{array}$ & 60.0 & 13.3 & 26.7 \\
\hline $\begin{array}{l}10 \mu \mathrm{M} \mathrm{Mg}{ }^{2+} \\
500 \mathrm{nM} \mathrm{G}\end{array}$ & 53.2 & 24.2 & 22.6 \\
\hline
\end{tabular}

Survey of P2-P3 dynamic behavior

\begin{tabular}{|l|l|l|l|}
\hline Buffer & $\begin{array}{l}\% \\
\text { slow }\end{array}$ & $\begin{array}{l}\% \\
\text { fast }\end{array}$ & $\begin{array}{l}\% \\
\text { both }\end{array}$ \\
\hline $\begin{array}{l}0 \mu \mathrm{M} \mathrm{Mg}{ }^{2+} \\
0 \mathrm{nM} \mathrm{G}\end{array}$ & 19.6 & 15.9 & 64.5 \\
\hline $\begin{array}{l}0 \mu \mathrm{M} \mathrm{Mg}{ }^{2+} \\
500 \mathrm{nM} \mathrm{G}\end{array}$ & 19.3 & 16.9 & 63.9 \\
\hline
\end{tabular}


Figure S4. Stabilization by guanine of the high- $E$ state of the P2-P3 variant.

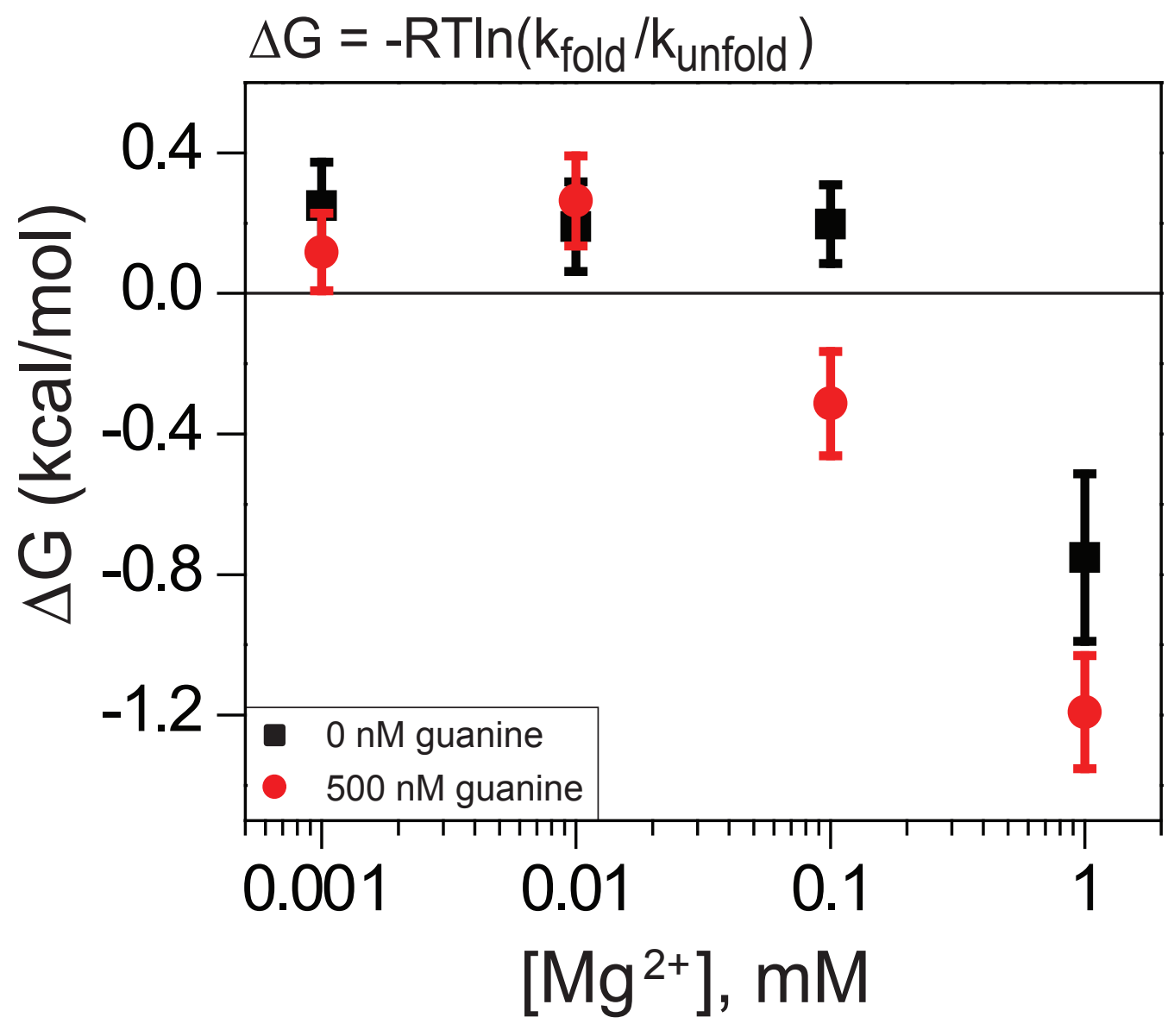




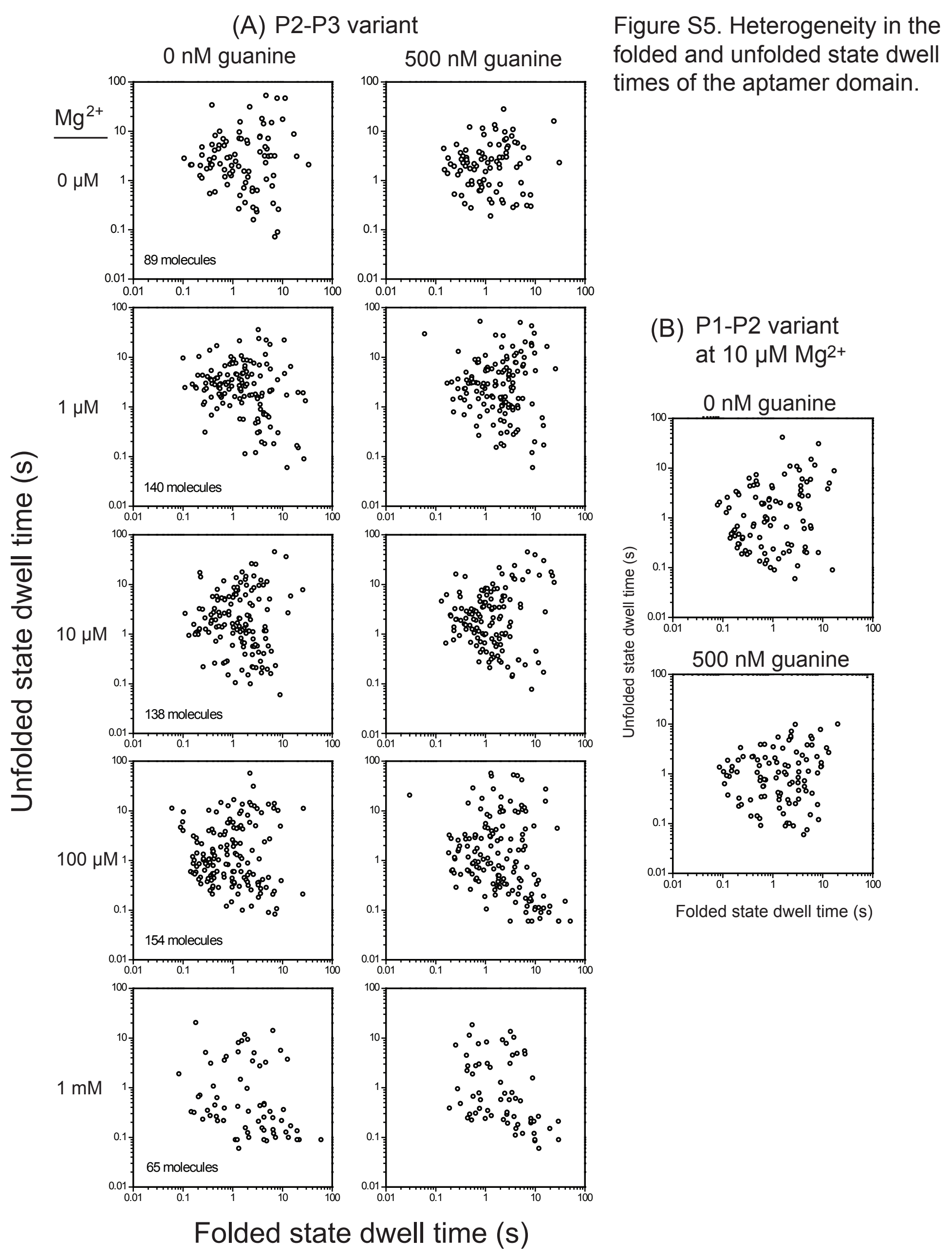

